\begin{tabular}{|c|c|c|}
\hline $\begin{array}{l}\text { PKS } \\
\text { PUBLIC } \\
\text { KNOLEDGE } \\
\text { ROOLIEC }\end{array}$ & $\begin{array}{c}\text { REVISTA DE GEOGRAFIA } \\
\text { (RECIFE) } \\
\text { nttp://ww.rvistaufpe.br/revistageografia }\end{array}$ & $\begin{array}{l}\text { OJS } \\
\frac{\text { OPEN }}{\text { OPENAL }} \text { JYUNAL } \\
\text { GYSTMS }\end{array}$ \\
\hline
\end{tabular}

\title{
CORRELAÇÃO CRONOESTRATIGRÁFICA DOS DEPÓSITOS QUATERNÁRIOS DO PLANALTO SEDIMENTAR DO ARARIPE: UM ESTUDO DE CASO A PARTIR DOS MATERIAIS ENCONTRADOS NO MUNICÍPIO DE CRATO E BARBALHA - SUL DO CEARÁ
}

\author{
Flávia Jorge de Lima ${ }^{1}$, Antônio Carlos de Barros Corrêa ${ }^{2}$ \\ ${ }^{1}$ Professora da Universidade Federal de Alagoas. E-mail: flavia.limageo@gmail.com \\ ${ }^{2}$ Professor da Universidade Federal de Pernambuco. E-mail: dbiase2001@terra.com.br
}

Artigo recebido em 10/12/2017 e aceito em 09/03/2018

\begin{abstract}
RESUMO
No intuito de compreender a evolução do Planalto Sedimentar do Araripe, Lima (2015) mapeou as áreas de sedimentos quaternários, e aplicou a abordagem morfoestratigráfica associada à datação por Luminescência Opticamente Estimulada (LOE). Com esses dados buscou-se estabelecer uma correlação cronoestratigráfica dos depósitos quaternários, a partir dos materiais encontrados no município de Crato e Barbalha, sul do Ceará. Para isso foram coletadas amostras para granulometria e obtenção das idades pelo método LOE. As informações resultantes permitem concluir que o padrão de sedimentação é, atualmente, o principal fator condicionante da produção de sedimento da área. O preenchimento dos setores côncavos das encostas ao longo do Pleistoceno Superior/início do Holoceno, por meio das perturbações climáticas incididas no equilíbrio geomórfico das superfícies, resultou em superfícies deposicionais cuja morfologia atual é de encosta com certa convexidade e colinas alongadas, caracterizando feições.
\end{abstract}

Palavras-chave: Quaternário Tardio; Datação; Superfície deposicional

\section{CHRONOSTRATIGRAPHIC CORRELATION OF THE QUATERNARY DEPOSITS OF THE ARARIPE SEDIMENTARY PLATEAU: A CASE STUDY FROM THE MATERIALS FOUND IN THE MUNICIPALITY OF CRATO AND BARBALHA - SOUTH OF CEAR}

\begin{abstract}
In order to understand the evolution of the Araripe Sedimentary Plateau, Lima (2015) mapped the areas of quaternary sediments, and applied the morphostratigraphic approach associated with dating by Optically Stimulated Luminescence (LOE). With this data, we attempted to establish a chronostratigraphic correlation of the quaternary deposits, from the materials found in the municipality of Crato and Barbalha, south Ceará. For this, samples were collected for grain size and age attainment by LOE method. The resulting information allows to conclude that the sedimentation pattern is currently the main conditioning factor of sediment production in the area. The filling of the concave slopes along the upper Pleistocene / early Holocene, through the climatic perturbations of the geomorphic balance of the surfaces, resulted in depositional surfaces whose present morphology is sloping with a certain convexity and elongated hills, characterizing features typical of inversion of relief.
\end{abstract}

Key-words: Upper Quaternary; dating; deposition surface 


\section{INTRODUÇÃO}

Por muito tempo as dificuldades de estabelecer uma correlação entre os processos de denudação e formas associadas constituíram-se em um problema para a geomorfologia do Quaternário. Tais dificuldades se arrastaram desde as inúmeras inquietações surgidas com os modelos generalistas das superfícies de aplainamento, no qual a correlação dava-se, em linhas gerais, por posicionamento topográfico.

Ainda que houvesse o reconhecimento da importância dos depósitos rudáceos como suporte de elucidação dos processos formadores da paisagem geomorfológica, não havia correlações geocronológicas bem definidas que pudessem ser associadas aos dados sedimentológicos e/ou estratigráficos.

Sabe-se que a amplitude temporal e processual do período Quaternário oportuniza o desenvolvimento de pesquisas que tenham como foco a compreensão dos processos responsáveis pelo arranjo das diferentes formas da paisagem. De acordo SALGADOLABOURIAU (2007, p. 2) "A maior parte das paisagens dos continentes atuais é de origem geológica relativamente recente e os processos que as modificaram continuam atuando", e que as marcas deixadas na superfície ainda não foram totalmente destruídas pela erosão e/ou meteorização, condição que possibilita uma reconstrução aproximada dos processos formadores do Quaternário Tardio, ou seja, do final do Pleistoceno e Holoceno.

Desse modo, se a história evolutiva ao longo do Cretáceo é essencial para o entendimento das organizações morfoestruturais da região em megaescala, o conhecimento dos eventos de maior atividade geomórfica nas encostas é imprescindível para entender como os sistemas ambientais estão organizados ou se organizam ao longo do Quaternário Tardio.

Atualmente, ainda que o número de trabalhos seja exíguo e espacialmente disperso, já é possível, por meio de correlações, traçar um esboço da evolução da paisagem do Nordeste (NE) para o final do Pleistoceno e todo Holoceno. Um dos setores do Nordeste que se destaca pela produção crescente de dados é a região compreendida pela Província Borborema, contexto regional no qual se encontra a Bacia Sedimentar do Araripe.

Dentre os trabalhos, sublinha-se o de Corrêa (2001) que estudou a dinâmica geomorfológica do maciço da serra da Baixa Verde/PE, um dos compartimentos elevados do Planalto da Borborema. Para Corrêa (2001, p. 360/361) "as coberturas superficiais desta área do planalto da Borborema são de origem recente e não vão além do UMG, uma vez que a unidade mais antiga foi datada em cerca de 20.000 anos". 
No intuito de compreender a evolução da paisagem geomorfológica do Planalto Sedimentar do Araripe, Lima (2015) mapeou as áreas de retenção de sedimentos quaternários, e aplicou a abordagem morfoestratigráfica associada à técnica de datação por Luminescência Opticamente Estimulada (LOE). Os dados obtidos permitiram realizar uma interpretação, de natureza qualitativa e probabilística, da dinâmica ambiental dos depósitos situados no setor subúmido do planalto.

Com base nessas informações, objetiva-se com este trabalho estabelecer uma correlação cronoestratigráfica dos depósitos quaternários do Planalto Sedimentar do Araripe, a partir dos materiais encontrados no município de Crato e Barbalha, sul do Ceará (Figura $01)$.

Figura 01 - Localização da área de estudo.

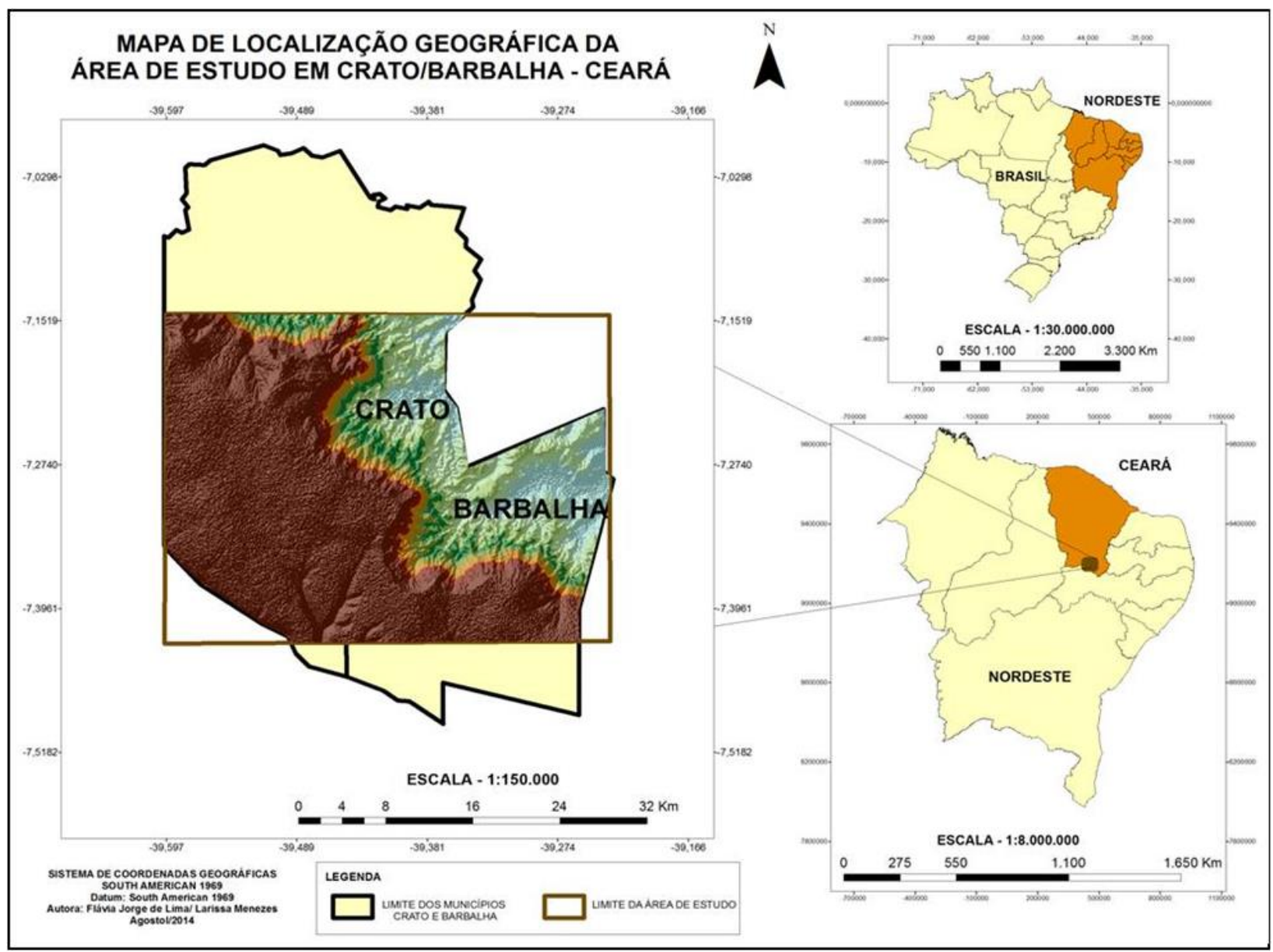




\section{MATERIAIS E MÉTODOS}

\section{Área de estudo}

O Planalto Sedimentar do Araripe, cuja cimeira estrutural está em torno de 960 metros, compreende uma das superfícies elevadas do interior do nordeste e é sustentado pelos terrenos paleo-mesozóicos da Bacia Sedimentar do Araripe (sub- bacia leste - vale do Cariri), uma bacia intracratônica do tipo rifte (SOUZA, 2000; NEUMANN et al., 2003; SILVA et al, 2003). Essa morfoestrutura encontra-se modelada em superfícies mantidas tanto pelo material sedimentar da bacia quanto pelas coberturas quaternárias na forma de colúvio, colúvio-alúvio e alúvio. São superfícies demarcadas na paisagem por colinas convexas alongadas, encostas dissecadas com rampas de colúvio, fundos de vales abertos, planícies e glacis dissecados (LIMA, 2015).

A paisagem também se destaca por dois fatores: a composição fitogeográfica e o tipo de clima. O primeiro, por apresentar um arranjo vegetal composto pelas seguintes fitofisionomias: Cerrado/cerradão e mata úmida a partir da cota de 700m; mata seca na média encosta; e caatinga arbórea- arbustiva na baixa encosta em direção às áreas de planícies, onde existem fragmentos de mata ciliar (ANDRADE-LIMA,1966; FUNCEME, 2006; FERNANDES, 2006).

O segundo, pela diferenciação climática em relação ao contexto geral semiárido que, devido à influência direta do efeito orográfico, exibe um topoclima cuja fisionomia da paisagem denuncia, de imediato, as alterações nos padrões de temperatura e umidade. Conforme a classificação de Köppen trata-se de um clima tropical chuvoso, tipo Aw, subúmido seco (IBGE, 2002; FUNCEME, 2012; 2015), com estação chuvosa no verão/outono. As temperaturas médias anuais oscilam entre 23 a $27^{\circ} \mathrm{C}$, e a pluviosidade média anual entre 1000 e $1.100 \mathrm{~mm}$. 


\section{Metodologia}

Reconhecidas as feições deposicionais em campo, foram coletadas amostras para granulometria e obtenção das idades pelo método Luminescência Opticamente Estimulada.

As análises granulométricas permitiram caracterizar de forma quantitativa e qualitativa os sedimentos, seguindo as orientações da metodologia de peneiramento das amostras de Gale e Hoare (1991), empregando a escala de Wentworth para definição das classes do tamanho das partículas. As datações dos sedimentos por LOE foram realizadas na empresa Datação, Comércio \& Prestação de Serviços LTDA, em São Paulo/SP. Todas as seções foram descritas utilizando-se de critérios litoestratigráficos (LIMA, 2015).

\section{RESULTADOS E DISCUSSÕES}

Constata-se uma concentração de idades ao longo do período de 40.000 à 13.000 AP, coincidindo com o final do último interestadial, bem como todo o Ultimo Máximo Glacial UMG. Este é caracterizado por amplas alterações no ambiente tropical do Brasil, incluindo o semiárido nordestino, como observado por Behling et al (2000), Correa (2001), Barreto (2010), Silva (2013) e Mutzenberg (2010). Barreto (2010), ao estudar as estalagmites na Chapada Diamantina, constatou que no período de 80.000-69.000 e de 57.000-47.000 AP as condições climáticas eram mais secas. Essas condições podem ter alterado o comportamento das encostas, gerando pulsos de sedimentação na chapada do Araripe (Figura 02). 
Figura 02 - Correlação cronoestratigráfica das seções

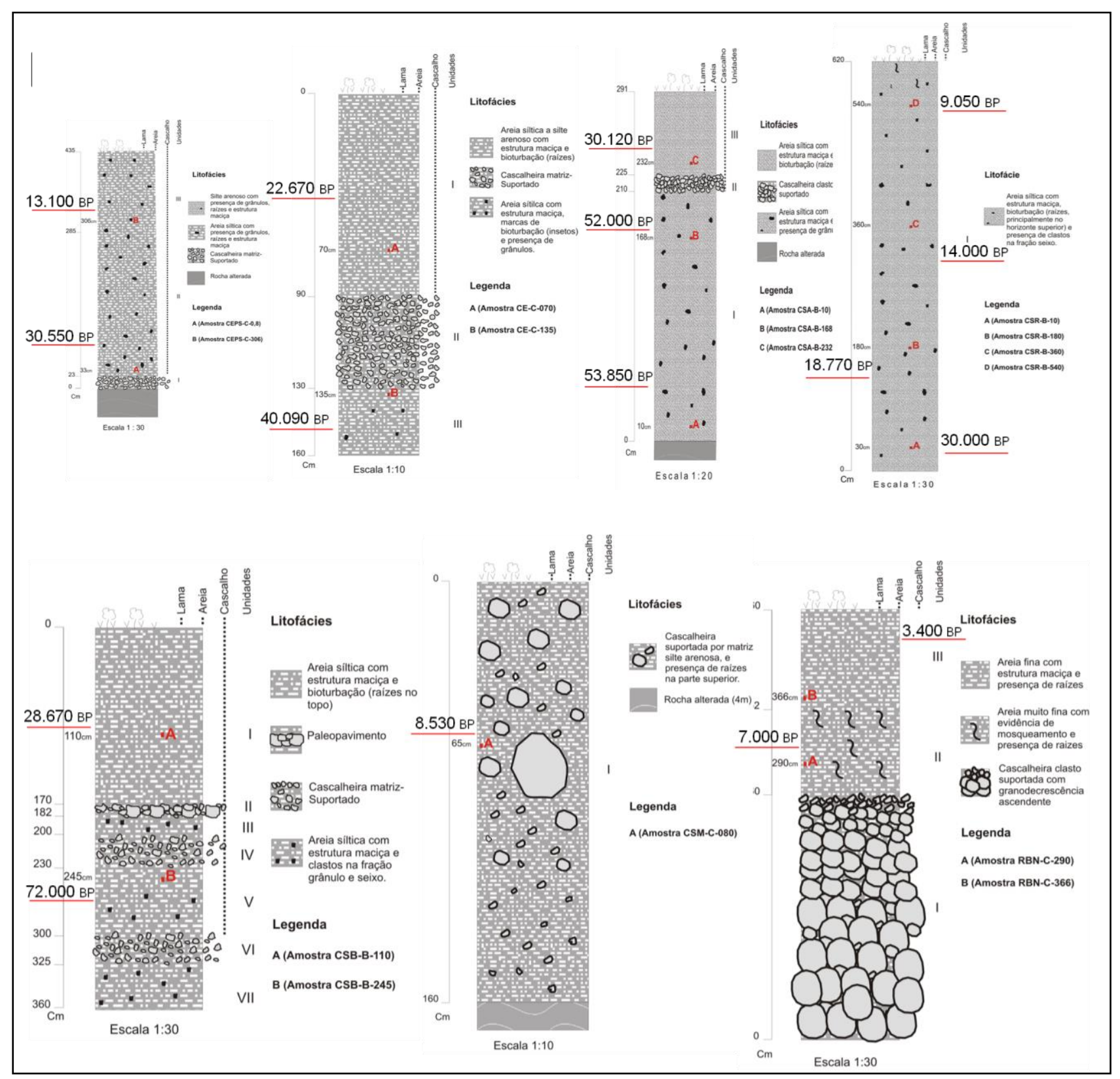

Ressalta-se que entre 40.000 e 20.000 AP predominaram as condições secas. Tais considerações dialogam com as de Silva (2013) quando enfatiza que o UMG na região NE foi mais seco e frio, com temperaturas rebaixadas em torno de $6^{\circ}$ (BEZERRA et al, 2008), e que a ocorrência de ampla sedimentação de encosta no interior do NE poderia ser explicada pela entrada de ar polar sobre as baixas latitudes tropicais, causando instabilidade no sistema atmosférico cuja consequência seria a formação de intensas chuvas frontais. Esses depósitos estariam associados a momentos de intensa torrencialidade climática no UMG (CORREAA, 2001; PESSENDA et al, 2010; e BEHLING et al 2000). 
Apenas dois perfis apresentaram registros do Holoceno Superior. Trata-se de um fluxo de lama, unidade superficial do perfil CSR-B, e um fluxo de detritos de alta energia, com morfologia indicativa de um setor proximal de leque coluvial. Nos demais, as deposições finais não ultrapassam o ápice do UMG.

Tal aspecto remete a dois cenários interpretativos: o material de recobrimento mais recente fora removido do sistema de encosta ao longo do Holoceno, e depositado nas áreas contiguas as drenagens, constituindo as planícies hodiernas; a paisagem esteve submetida a um longo tempo de não deposição, sem que o clima tivesse conseguido obliterar as características deposicionais herdadas pelos materiais.

Apenas um perfil não documenta a ocorrência de fluxo de detritos, o CSR-B. Todavia a sua unidade basal, datada de 30.700 AP, é temporalmente correlativa aos depósitos de fluxo de lama que recobrem as cascalheiras, permitindo inferir idade limite superior de deposição de 30.000 AP.

Quanto ao seu limite inferior, pode-se aventar com base nas unidades basais dos perfis CSR-B, CE-C e CSA-B, que corresponde aproximadamente à isócrona de 40.000 AP. Observa-se que no transcurso desse período ocorreu uma intensa remoção dos depósitos de tálus situados na base da escarpa, à montante, que, por seu turno, passaram a ocupar espaços de acomodação de geometria côncava à jusante, preenchendo-os completamente. Possivelmente, esse período marca um momento de retração da cobertura vegetal sob influência de um clima mais frio e seco, no qual a ação pulsátil das precipitações torrenciais fora eficiente na remobilização das frações rudáceas de tamanhos variados, como blocos, e sua posterior redistribuição ao longo das encostas.

Esse cenário, talvez, tenha acompanhado um discreto melhoramento climático ao longo do Último Interestadial, com ligeiro aumento de temperatura (BRADLEY e JONES, 1995) e participação de eventos pluviométricos de alta magnitude e baixa frequência. Em alguns perfis, as cascalheiras apresentam-se com matriz apenas de natureza intersticial, sugerindo que até a ocorrência de uma nova fase deposicional, por volta de 30.000 AP, dependendo do perfil, estiveram submetidas à égide dos processos superficiais de erosão laminar com evacuação dos finos.

Provavelmente as condições mais secas não favoreceram o restabelecimento da cobertura vegetal. A sedimentação de encosta na área de estudo não ultrapassa o Holoceno Inferior, entretanto são necessárias mais datações/dados para confirmar de fato tal assertiva. 
De todo o modo, verifica-se que assim como atestado nos demais trabalhos produzidos ao longo da Província Borborema, esse período foi marcado por instabilidade ambiental bem assinalada nas encostas, possivelmente em decorrência de um rearranjo do sistema à rápida melhoria climática ocorrida no final e transição pleistoceno/Holoceno, com altos níveis de precipitação e estabelecimento de uma cobertura vegetal mais densa (TINTELNOT, 1996 apud MUTZENBERG, 2010).

No âmbito dessa fase de transição, duas unidades deposicionais documentam as bruscas mudanças ambientais ocorridas na área: um fluxo de detritos com características de alta energia, CSM-C-080; e os fluxos de lama que encerram o conjunto deposicional do perfil CSR-B, assim como a unidade superior do perfil CEPS-C. De acordo com Behling et al (2000), tal padrão pode ser explicado pelo deslocamento anual da ZCIT, sistema atuante na área, e pela forte influência das frentes frias provenientes da Antártida e mudanças das células de alta pressão sobre o Atlântico Sul.

A abrangência temporal dialoga com os dados fornecidos por Barreto (1996), De Oliveira, Barreto e Suguio (1999), Gouveia et al (2005) e Pessenda et al (2010) para o limiar do Holoceno Superior. Nesse contexto destacam-se os trabalhos de Gouveia et al (2005) e Pessenda et al (2010) que apontam para uma redução, também brusca, da umidade ao entrar no Holoceno, possivelmente entre 10.000-9.000 AP, observada pelo aumento da expansão do cerrado.

Essas oscilações rápidas da umidade que afetaram a região resultaram nas duas últimas unidades deposicionais documentadas sob o comando dos processos ligados à dinâmica de encosta. O fluxo de detritos de alta energia, contendo blocos de tamanhos variados, reflete uma ampliação das formações vegetais abertas e a exposição dos depósitos de tálus a movimentos de massa de elevado poder de remobilização das coberturas rudáceas sob condição de forte torrencialidade.

Contudo, a redução geral da umidade não significou necessariamente uma transição para o modo climático de semiaridez acentuada com secas constantes comum ao ambiente semiárido nordestino, pois em outras áreas do NE a transição do Holoceno/Pleistoceno, no intervalo de 15.000 a 8.000 AP, foi marcada por uma fase de reumidificação geral. Idades do Holoceno Médio e Superior foram encontradas no perfil estudado às margens de um canal, no qual observou uma cascalheira basal de espessura considerável. As duas unidades sobrejacentes à cascalheira foram datadas respectivamente de 7.000 e 3.400 AP. Estes 
depósitos suscitam que a partir de 7.000 AP a drenagem ganhou força para entalhar os fundos de vales, entrincheirando as cascalheiras basais e redefinindo o nível de base local.

Tal deposição de 7.000, testemunha também o aumento na capacidade de deflúvio e remobilização de sedimentos, provavelmente ligada ao período conhecido por Hipsotérmico ocorrido entre 7.600 e 4.500 AP e tratado como o mais quente e úmido do atual interglacial para o Nordeste do Brasil. O segundo momento de deposição nas margens desse canal aconteceu por volta de 3.400 anos, coincidindo com o período de retorno da subumidade atual proposto por Gouveia et al (2005) e Pessenda et al (2010).

O padrão climático subúmido contemporâneo reflete-se nos processos geomórficos vigentes na paisagem, dentre os quais predominam o ravinamento, voçorocamento e escoamento superficial não canalizado. Comparando-se com o padrão da sedimentação encontrado nas demais áreas da Província Borborema, pode-se aventar que no setor subúmido da Chapada do Araripe, a remobilização extensiva dos depósitos de tálus e da cobertura pedológica por movimentos de massa de alta energia não ocorrem, pelo menos desde os últimos $8.000 \mathrm{AP}$, ou, se ocorreram, seus depósitos resultantes não estão mais acomodados nos ambientes de encosta, havendo sido expulsos desse sistema e redistribuídos longitudinalmente nos fundos de vales e canais.

\section{CONSIDERAÇÕES FINAIS}

O preenchimento das áreas côncavas das encostas ao longo do Pleistoceno Superior/início do Holoceno, por meio das perturbações climáticas incididas no equilíbrio geomórfico das superfícies, resultou em superfícies deposicionais cuja morfologia atual é de encosta com certa convexidade e colinas alongadas, caracterizando feições típicas de inversão de relevo. Nesse caso, controladas por pulsos climáticos de alta magnitude e baixa recorrência, sem necessariamente existir uma continuidade prolongada dos processos formativos como colocava Thomas (1994).

Dois intervalos marcam situações de maior atividade morfogenética nas encostas: 1De 40.000 a 30.000 anos AP, período em que ocorreu uma ampla formação de depósitos por fluxos de detritos de baixa viscosidade e não canalizados, frutos da remobilização maciça dos depósitos de tálus em resposta a possíveis eventos pluviométricos de alta energia e baixa recorrência sobre uma superfície exposta; 2 - De 30.000 a 18.000 AP, sucessivos fluxos de lama generalizados pela paisagem recobriram a superfície dos fluxos de detritos anteriores. 
Estes sinalizam a continuidade dos processos morfogenéticos na esculturação das encostas e no recuo da cimeira estrutural do planalto sedimentar, submetidas aos eventos de chuvas torrenciais comuns ao Nordeste continental, resultantes da instabilidade climática associada ao UMG com clima mais frio e seco.

\section{AGRADECIMENTOS}

À CAPES, pela bolsa de Doutorado; ao Programa de Pós-Graduação em Geografia da Universidade Federal de Pernambuco - UFPE.

\section{REFERÊNCIAS}

ANDRADE-LIMA, D. Vegetação. In: IBGE. Atlas Nacional do Brasil. Rio de Janeiro: Conselho Nacional de Geografia, 1966.

BARRETO, A. M. F. Interpretação Paleoambiental do Sistema de Dunas Fixadas do Médio São Francisco, Bahia. 1996. 174 f. Tese (Doutorado em Geologia) - Universidade de São Paulo, SP, 1996.

BARRETO, E. A. S. Reconstituição da pluviosidade da chapada diamantina (BA) durante o Quaternário tardio através de registros isotópicos (O e C) em estalagmites. 2010. 112 f. Dissertação (Mestrado em Geoquímica e Geotectônica) - Umiversidade de São Paulo, São Paulo, SP, 2010.

BEHLING, H. et al. Late Quaternary vegetational and climatic dynamics in northeastern Brazil, inferences from marine core GeoB 3104-1. Quaternary Science Reviews, v.19, p. 981994, 2000.

BEZERRA, F. H. R.; BRITO NEVES, B. B.; CORRÊA, A. C. B., BARRETO, A. M. F.; SUGUIO, K. Late Pleistocene tectonic-geomorphological development within a passive margin - The Cariata trough, northeastern Brazil. Geomorphology, v.97.p.555-582. 2008.

BRADLEY, R.S. e JONES, P.D. Climate Since A.D. 1500: Introduction. In: BRADLEY, R.S. e JONES, P.D (Eds.). Climate Since A.D. 1500. London: Routledge, revised edition, 1995, p. $1-16$.

CORRÊA, A. C. B. Dinâmica geomorfológica dos compartimentos elevados do Planalto da Borborema, Nordeste do Brasil. 2001. 386 f. Tese (Doutorado em Geografia) - Universidade Estadual Paulista, Rio Claro, SP, 2001.

DE OLIVEIRA, P. E., BARRETO, A. M. F. e SUGUIO, K. Late Pleistocene/Holocene climatic and vegetational history of the Brazilian caatinga: the fossil dunes of the middle São 
Francisco River. Palaeogeography, Palaeoclimatology, Palaeoecology, v. 152, p. 319-337, 1999.

FERNANDES, A. Fitogeografia brasileira - Províncias florísticas. 2a parte. 3. ed. Fortaleza: Realce editora e indústria gráfica, 2006.

FUNDAÇÃO CEARENSE DE METEOROLOGIA E RECURSOS HÍDRICOS (FUNCEME), Zoneamento geoambiental do Ceara: Parte II - Mesorregião do sul cearense. Fortaleza, 2006

. Levantamento de reconhecimento de média intensidade dos solos - Mesorregião do Sul Cearense. Fortaleza, 2012. 280p. Índice de Aridez para o Ceará. Acesso em maio de 2015.

GALE, S. J. \& HOARE, P. G. Quaternary sediments: petrographic methods for the study of ulithified rocks. Londres: Bethaven Press, 1991, 318 p.

GOUVEIA, S. E. M. et al. Reconstrução paleoambiental (vegetação e clima) no nordeste do Brasil através dos isótopos do carbono da matéria orgânica dos solos e fragmentos de carvão. In: X Congresso da Abequa, Espirito Santo, 2005

LIMA, F. J. de. Evolução geomorfológica e reconstrução paleoambiental do setor subúmido do Planalto Sedimentar do Araripe: um estudo a partir dos depósitos coluviais localizados nos municípios de Crato e Barbalha - Ceará. 2015. 192 f. Tese (Doutorado em Geografia) Universidade Federal de Pernambuco, Recife, PE,2015.

MUTZENBERG, D. S. Ambientes de Ocupação Pré-Histórica no Boqueirão da Pedra Furada, Parque Nacional Serra da Capivara - PI. 2010. 256 f. Tese (Doutorado em Arqueologia) Universidade Federal de Pernambuco, Recife, PE, 2010.

NEUMANN, V. H. de M. L et al. Organic matter composition and distribution through the Aptian-Albian lacustrine sequences of the Araripe Basin, northeastern Brazil. International Journal of Coal Geology. v. 54, p. 21-40, 2003.

PESSENDA, L. C. R. et al. Late Pleistocene and Holocene vegetation changes in northeastern Brazil determined from carbon isotopes and charcoal records in soils. Palaeogeography, Palaeoclimatology, Palaeoecology, v. 297, p. 597-608, 2010.

PIMENTEL, F. V. Reconstrução da precipitação sobre o Nordeste brasileiro em função das temperaturas da superfície do mar durante o Holoceno. 2013. 95 f. Dissertação (Mestrado em Ciências Físicas Aplicadas) - Universidade Estadual do Ceará, Fortaleza, CE, 2013.

SALGADO-LABOURIAU, M. L. Critérios e técnicas para o Quaternário. São Paulo: Edgard Blucher, 2007 
SILVA, A. J. P.; LOPES, R. da C.; VASCONCELOS, A. M.; BAHIA, R. B. C. Bacias Sedimentares Paleozóicas e Meso-Cenozóicas Interiores. In: BIZZI, L. A.; SCHOBBENHAUS, C.; VIDOTTI, R. M.; GONÇALVES, J. H. (org.) Geologia, Tectônica e Recursos Minerais do Brasil. Brasília: CPRM, 2003. p. 55-85.

SILVA, D. G. da. Reconstrução da dinâmica geomorfológica do semiárido brasileiro no Quaternário superior a partir de uma abordagem multiproxy. 2013. 277 f. Tese (Doutorado em Geografia) - Universidade Federal de Penambuco, Recife, PE, 2013.

SOUZA, M. J. N. Bases naturais e esboço do zoneamento geoambiental do estado do Ceara. In: LIMA, L. C. (Org) Compartimentação territorial e gestão regional do Ceará. Fortaleza: Funece, 2000. p. 06-104.

THOMAS, M. F. Geomorpholoqy in the Tropics: a study of weatherinq and denudation in low latitudes. Chichester: John Wiley \& Sons, Ltd., 1994. 